\title{
Modeling and Analysis of Two Wheeler Connecting Rod by Using Ansys
}

\author{
B. Anusha ${ }^{1}$, C.Vijaya Bhaskar Reddy ${ }^{2}$ \\ $\left({ }^{1}\right.$ Department of Mechanical Engineering, P.G Student, Sri Kalahasteeswara,Institute of Technology, \\ Srikalahasti, ) \\ ( ${ }^{2}$ Sr.Asst.Prof, Department of Mechanical Engineering, srikalahasti, )
}

\begin{abstract}
Connecting rod is a major link inside of a internal combustion engine. It is the intermediate member between the piston and the crankshaft. Its primary function is to transmit the push and pull from the piston pin to the crank pin thus converting the reciprocating motion of piston in to rotary motion of the crank. In this paper a static analysis is conducted on a connecting rod of a single cylinder 4-stroke petrol engine. The model is developed using Solid modeling software i.e. PRO/E (creo-parametric). Further finite element analysis is done to determine the von-misses stresses shear stress and strains for the given loading conditions.
\end{abstract}

Keywords - ANSYS Workbench, connecting rod, Finite Element analysis, PRO/E (creo-parametric).

\section{Introduction}

Connecting rod is among large volume production component in the internal combustion engine. It connects the piston to the crankshaft and is responsible for transferring power from the piston to the crankshaft and sending it in to transmission. They are different types of materials and production methods used in the creation of connecting rods. The major stresses induced in the connecting rod are a combination of axial and bending stresses in operation. The axial stresses are produced due to cylinder gas pressure (compressive only) and the inertia force arising in account of reciprocating action (both tensile as well as compressive), where as bending stresses are caused due to the centrifugal effects. It consists of a long shank, a small end and a big end. The cross-section of the shank may be rectangular, circular, tubular, I-section or H-section. Generally circular section is used for low speed engines while I-section is preferred for high speed engines. The most common type of manufacturing processes is casting, forging, and powdered metallurgy. Connecting rod is subjected to a complex state of loading. It undergoes high cyclic loads of the order of $10^{\wedge} 8$ to $10^{\wedge} 9$ cycles, which range from high compressive loads due to combustion, to high tensile loads due to inertia. Therefore, durability of this component is critical importance. Due to these factors, the connecting rod has been the topic of research for different aspects such as production technology, materials, performance, simulation, fatigue etc.

Vivek.c.pathade et al[1] performed stress analysis of I.C Engine connecting rod by finite element method. They modeled connecting rod using pro/E Wildfire 4.0 and ANSYS Workbench 11.0 software. They reported from the theoretical and finite element analysis then the stresses induced in the small end of the connecting rod are greater than the stress induced at the big end. K.surdershn Kumar et al [2], reported on modeling and analysis of two wheeler connecting rod. In this connecting rod is replaced by aluminum reinforced with boron carbide for Suzuki GS150R motor bike. A parametric model of connecting rod is modeled using pro/E Wildfire 4.0. Analysis is carried out by using ANSYS software. They presented the results of materials and reported that the working factor of safety is nearer to theoretical factor of safety in aluminum boron carbide. Anil Kumar et al [3], presented the optimization of connecting rod parameters using CAE tools. They reported on optimizing weight and reducing inertia forces on the existing connecting rod, which is obtained by changing design variables in the existing connecting rod design. The model was developed in pro/E Wildfire 5.0 and then imported as a Para solid (xt) from in ANSYS Workbench. The stress was found maximum at the piston end. This can be reduced by increasing the material near the piston end. The weight of the connecting rod was also reduced by $0.004 \mathrm{~kg}$ which was not significant but reduces the inertia forces. Suraj pal et al [4], reported on design evaluation and optimization of connecting rod parameters using Finite element method. Proper finite element model is developed using pro/E Wildfire 4.0. The weight of the connecting rod is also reduced by $0.477 \mathrm{~g}$. The stress is found maximum at the piston end so that material is increased in the stressed portion to reduce stress. Dr. S B Jaju et al [5], performed modeling and analysis of connecting rod of four stoke single cylinder engine for optimization of cost and material. Their study has dealt with two subjects first static load stress analysis of the connecting rod, and then second optimization for weight. 


\section{Modeling}

Connecting rod of Hero Honda splendor, market available is selected for the present investigation. The dimensions of the selected connecting rod are found using vernier calipers, screw gauge and are tabulated in the table1. According to the dimensions the model of the connecting rod is developed using PRO/E (creoparametric). The modeled connecting rod is shown in fig1. It is imported in to design modeler of ANSYS work bench.

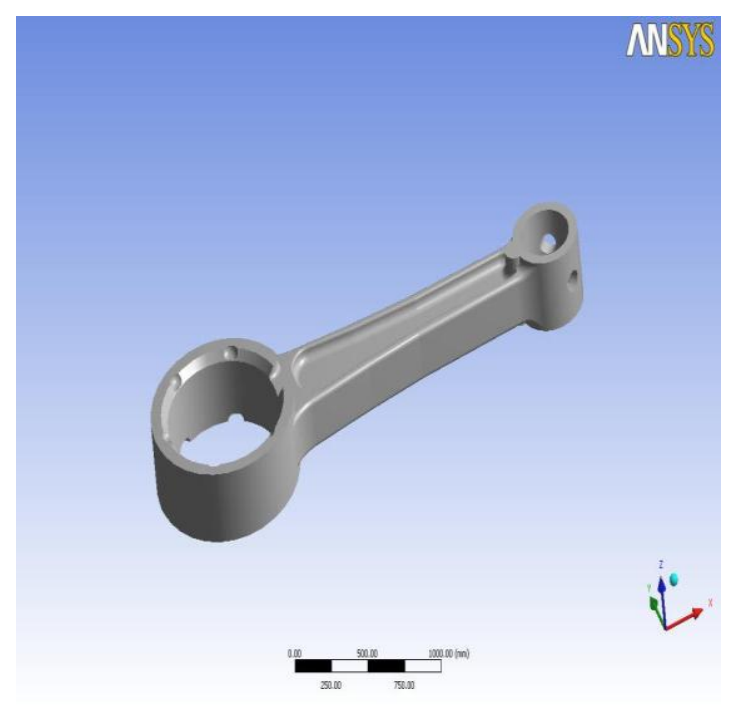

Fig1: Model of connecting rod

\begin{tabular}{|l|l|l|}
\hline S.no & Parameters & Values \\
\hline 1. & Length of connecting rod & $94.27 \mathrm{~mm}$ \\
\hline 2. & Outer Diameter of Big end & $39.02 \mathrm{~mm}$ \\
\hline 3. & Inner Diameter of Big end & $30.19 \mathrm{~mm}$ \\
\hline 4. & Outer Diameter of small end & $17.75 \mathrm{~mm}$ \\
\hline 5. & Inner Diameter of Small end & $13.02 \mathrm{~mm}$ \\
\hline
\end{tabular}

Table 1: Dimensions of connecting rod

\section{MATERIAL PROPERTIES}

The material used for selected connecting rod is cast iron and the properties of the material are presented in the Table 2 .

\begin{tabular}{|l|l|}
\hline Material Selected & Cast Iron \\
\hline Young's Modulus(E) & $1.78 \mathrm{e}+005 \mathrm{Mpa}$ \\
\hline Poisson's Ratio & 0.3 \\
\hline Density & $7.197 \mathrm{e}-006 \mathrm{Kg} / \mathrm{mm}^{\wedge} 3$ \\
\hline Tensile Strength & 100 to $200 \mathrm{Mpa}$ \\
\hline Compressive Strength & 400 to $1000 \mathrm{Mpa}$ \\
\hline Shear Strength & $120 \mathrm{Mpa}$ \\
\hline
\end{tabular}

Table 2: Properties of Cast Iron

\section{Meshing}

The next stage of the modeling is to create meshing of the created model. The below said parameters are used for meshing. The mesh model of connecting rod is as shown in fig 2 .

$\begin{array}{lll}\text { Type of Element } & : & \text { Tetrahedron } \\ \text { Number of Nodes } & : & 16076 \\ \text { Number of Elements } & : & 8373\end{array}$




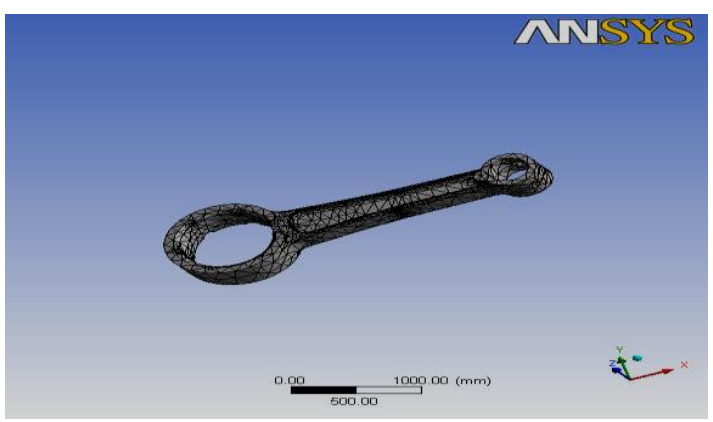

Fig 2: Mesh model of connecting rod

\section{Load Diagram Of Connecting Rod}

A PRO/E model of connecting rod is used for analysis in ANSYS Workbench. Analysis is done with the pressure of $3.15 \mathrm{Mpa}$ load applied at the piston end of the connecting rod and fixed at the crank end of the connecting rod. It is shown in Fig3.

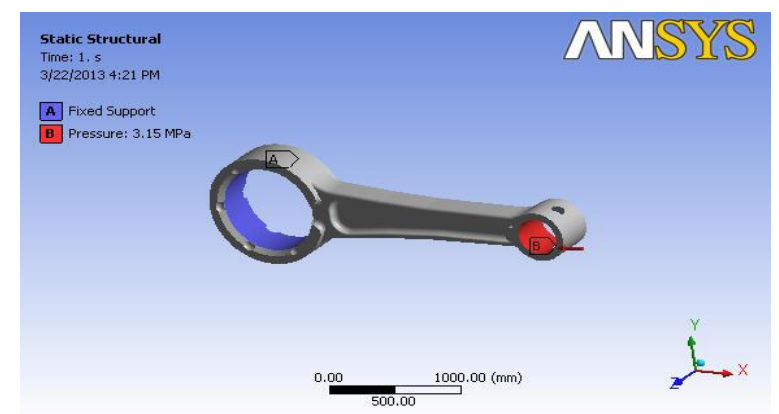

Fig 3: Loads and boundary conditions of connecting rod.

\section{Results And Dicussion}

For the finite element analysis 3.15Mpa of pressure is used. The analysis is carried out using PRO/E (creo-parametric) and ANSYS work bench software. The pressure is applied at the small end of connecting rod keeping big end fixed. The maximum and minimum von-misses stress, strain, shear stress, and factor of safety are noted from the ANSYS Work bench.

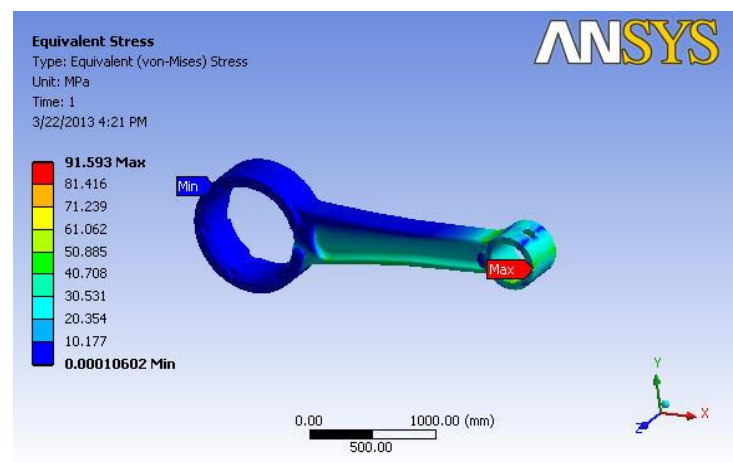

Fig 4: von-misses stress of connecting rod

From the fig 4 the maximum stress occurs at the piston end of the connecting rod is $91.593 \mathrm{Mpa}$ and minimum stress occurs at the crank end of the connecting rod is $1.06 \mathrm{e}-4 \mathrm{Mpa}$. 


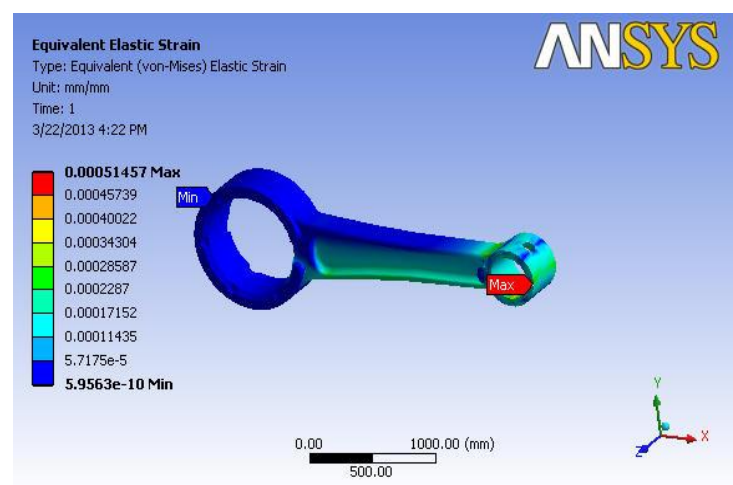

Fig 5: Elastic strain of connecting rod

From the fig 5 the maximum Equivalent elastic strain occurs at the piston end of the connecting rod is $0.000514 \mathrm{~mm}$ and minimum stress occurs at the crank end of the connecting rod is $5.95 \mathrm{e}-10 \mathrm{~mm}$.

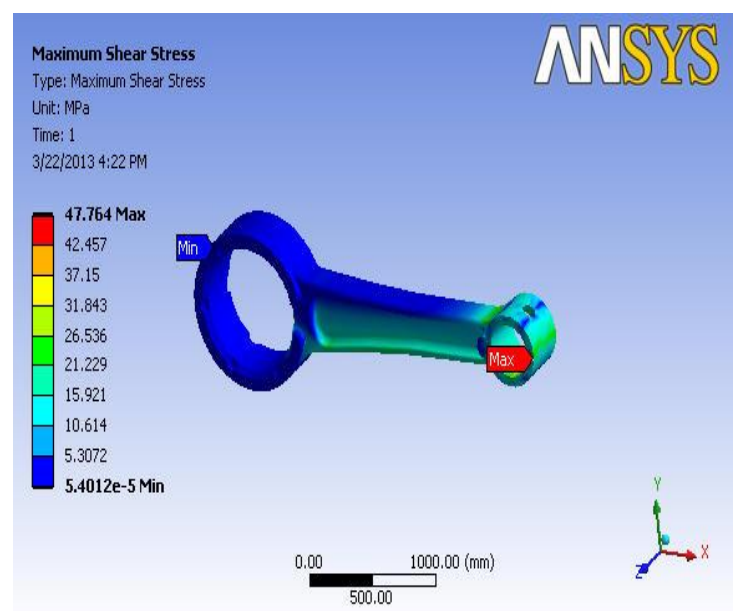

Fig 6: Shear stress of connecting rod

From the fig 6 the maximum shear stress occurs at the piston end of the connecting rod is $47.764 \mathrm{Mpa}$ and minimum stress occurs at the crank end of the connecting is 5.40e-5 Mpa.

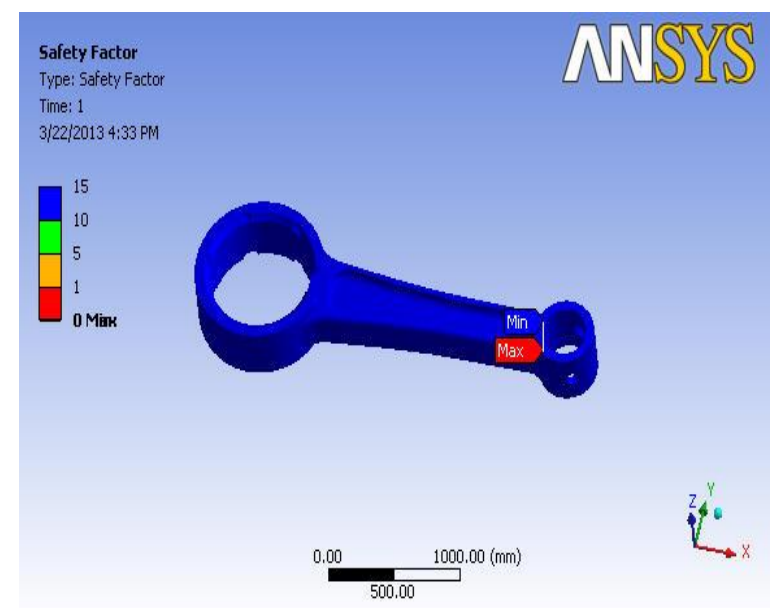

Fig 7: Factor of Safety of connecting rod 


\section{Conclusion}

Finite Element analysis of the connecting rod of a Hero Honda Splendor has been done using FEA tool ANSYS Workbench and are tabulated in table 3.

\begin{tabular}{|l|l|l|}
\hline Name & Maximum & Minimum \\
\hline Von-misses stress & $91.593 \mathrm{Mpa}$ & $1.06 \mathrm{e}-4 \mathrm{Mpa}$ \\
\hline Shear stress & $47.764 \mathrm{Mpa}$ & $5.40 \mathrm{e}-5 \mathrm{Mpa}$ \\
\hline Elastic strain & $0.000514 \mathrm{~mm}$ & $5.95 \mathrm{e}-10 \mathrm{~mm}$ \\
\hline
\end{tabular}

Table3: Static analysis of connecting rod

From the above table of static analysis, the stress induced by using ANSYS is less than the material allowable limit of stress. So the model presented here is well for safe design under given loading conditions.

From the static analysis the stress is found maximum at the piston end of the connecting rod

\section{References}

[1] Vivek.c.pathade, Bhumeshwar Patle, Ajay N. Ingale "Stress Analysis of I.C. Engine Connecting Rod by FEM", International Journal of Engineering and Innovative Technology, Vol-1, Issue-3, March2012.

[2] k. Sudershn Kumar, Dr. k. Tirupathi Reddy, Syed Altaf Hussan "Modeling and analysis of two Wheeler connecting rod", International Journal of Modern Engineering Research, Vol -2, Issue- 5,

Sep-Oct-2012.

[3] Anil Kumar, Kamaldeep Grover, Balvinder budina “optimization of connecting rod parameters using CAE tools", International Journal of Latest Trends in Engineering and Technology, Vol- 1, Issue- 3, Sep2012.

[4] Suraj Pal, Sunil Kumar, "Design Evaluation and Optimization of Connecting Rod Parameters Using FEM", International Journal of Engineering and Management Research, Vol- 2, Issue- 6, Dec 2012.

[5] Dr S B jaju, P G Chakra, "Modeling and Optimization of Connecting rod of Four Stroke Single Cylinder Engine for Optimization of cost and material". 